\title{
Crystal Structure Determination and Hydrogen-Bonding Patterns in 2-Pyridinecarboxamide
}

\author{
Gerzon E. Delgado*, Asiloé J. Mora, Marilia Guillén-Guillén, Jeans W. Ramírez, Jines E. Contreras \\ Laboratorio de Cristalografía, Departamento de Química, Facultad de Ciencias, Universidad de Los Andes, Mérida, Venezuela \\ Email: "gerzon@ula.ve
}

Received September 17, 2012; revised October 18, 2012; accepted October 26, 2012

\begin{abstract}
The title compound, 2-pyridinecarboxamide, $\mathrm{C}_{6} \mathrm{H}_{6} \mathrm{~N}_{2} \mathrm{O}$, crystallize in the monoclinic system with space group $\mathrm{P} 2{ }_{1} / \mathrm{n}$ $\left(\mathrm{N}^{\circ} 14\right), \mathrm{Z}=4$, and unit cell parameters $\mathrm{a}=5.2074(1) \AA, \mathrm{b}=7.1004(1) \AA, \mathrm{c}=16.2531(3) \AA, \beta=100.260(1)^{\circ}$. The crystal structure of the title compound, was reported previously from Weissenberg photographic data with $\mathrm{R}=0.127$. It has now been redetermined, providing a significant increase in the precision of the derived geometric parameters. The crystal packing is governed by $\mathrm{N}-\mathrm{H} \cdots \mathrm{O}$ hydrogen bond-type intermolecular interactions, forming infinite one-dimensional chains with graph-set notation $\mathrm{C}(4), \mathrm{R}_{2}^{2}(8)$ and $\mathrm{R}_{4}^{2}(8)$.
\end{abstract}

Keywords: Pyridinecarboxamides; Picolinamide; X-Ray Crystal Structure; Hydrogen Bonding

\section{Introduction}

The three isomers of pyridinecarboxamide; 2-pyridine carboxamide or picolinamide, 3-pyridinecarboxamide or nicotinamide and 4-pyridinecarboxamide or isonicotinamide are a class of medicinal agents which can be classified as GRAS (generally regarded as safe) compounds. In particular, nicotinamide (niacinamide, Vitamin B3) and picolinamide show important biological activity with a coenzyme called NAD (nicotinamide adenine dinucleotide), which plays important roles in more than 200 amino acid and carbohydrate metabolic reactions [1]. In general pyridinecarboxamides are excellent co-crystallizing compound. The amide group has two hydrogen bond donors and two lone pairs on the carbonyl $\mathrm{O}$ atom. A second hydrogen bond acceptor is the lone pair on the $\mathrm{N}$ atom of the pyridine ring. This makes these molecules very versatile for a variety of hydrogen bonded interactions, especially in pharmaceutical co-crystals [2-13]. The molecular structures and vibrational spectra of the three isomers has been the subject of recent theoretical studies [14,15], and from the crystal structure point of view, all isomer compounds exhibit polymorphism [12]. Nicotinamide has four polymorphs, the most stable crystallize in a monoclinic form [16], Isonicotinamide has three polymorphs in monoclinic and orthorhombic forms [17], and Picolinamide exists under two polymorphic structures [18]. The polymorph form with crystal structure in the Crystal Structure Database [19], was reported using Weissenberg photographic data and $\mathrm{R}=0.127$ [18].

${ }^{*}$ Corresponding author.
The present paper reports a redetermination of the crystal structure of 2-pyridinecarboxamide (picolinamide), with greater precision and accuracy. An analysis of the hydrogen-bonding patterns is also included.

\section{Experimental}

\subsection{Crystallization of the Title Compound}

Picolinamide crystals were obtained in an attempt to prepare 2-pyridinecarboxamide - amino acid co-crystals, in a 1:1 ethanol-water solution. Colorless crystals suitable for X-ray diffraction analysis were grown by slow evaporation from this solution (m.p. $375 \mathrm{~K}$ ).

\subsection{FT-IR and NMR Analysis}

Melting point was determined on an Electrothermal Model 9100 apparatus. The FT-IR absorption spectrum was obtained as $\mathrm{KBr}$ pellet using a Perkin-Elmer 1600 spectrometer. ${ }^{1} \mathrm{H}$ and ${ }^{13} \mathrm{C}$ NMR spectra were determined on a Bruker Avance 400 model spectrometer.

FT-IR: $1392 \mathrm{~cm}^{-1}$ (t, C-N), $1666 \mathrm{~cm}^{-1}$ (t, C= O), 3419 $\left.\mathrm{cm}^{-1}(\mathrm{t}, \mathrm{N}-\mathrm{H})\right] .{ }^{1} \mathrm{H}$ NMR $\left(400 \mathrm{MHz}\right.$, DMSO d $\left._{6}\right): \delta 8.63$ (d, H6, J = 4.8 Hz), 8.12 (s, H3), 8.05 (d, H1A, J= 7.9 $\mathrm{Hz}$ ), 7.98 (dt, H4, J1=15.4 Hz, J2 = 7.6 Hz, J3 = $1.7 \mathrm{~Hz}$ ), 7.65 (s, H5), 7.55 - 7.61 (m, H1B). ${ }^{13} \mathrm{C}$ NMR (100 MHz, $\left.\mathrm{DMSO} \mathrm{d}_{6}\right): \delta 166.0(\mathrm{C} 1), 150.3(\mathrm{C} 2), 148.4(\mathrm{C} 6), 137.6$ (C4), 126.4 (C5), 121.9 (C3).

\subsection{X-Ray Powder Diffraction}

$\mathrm{X}$-ray powder diffraction pattern was collected, at room 
temperature, in a Phillips PW-1250 goniometer using monocromatized $\mathrm{CuK} \alpha$ radiation $(\lambda=1.5418 \AA)$. A small quantity of picolinamide was ground mechanically in an agate mortar and pestle and mounted on a flat holder covered with a thin layer of grease. The specimen was scanned from $10^{\circ}-60^{\circ} 2 \theta$, with a step size of $0.02^{\circ}$ and counting time of $15 \mathrm{~s}$. Silicon was used as an external standard.

$\mathrm{X}$-ray powder pattern of picolinamide is shown in Figure 1. The 20 first measured reflections were completely indexed using the program Dicvol04 [20], which gave a unique solution in a monoclinic cell with parameters $\mathrm{a}=5.19 \AA, \mathrm{b}=7.09 \AA, \mathrm{c}=16.41 \AA, \beta=100.26^{\circ}$. In order to confirm the unit cell parameters, a Le Bail refinement [21] of the whole diffraction pattern without structural was carried out using the Fullprof program [22]. Figure 1 shows a very good fit between the observed and calculated patterns.

\subsection{X-Ray Single-Crystal Crystallography}

Colorless rectangular crystal $\left(0.37 \times 0.20 \times 0.20 \mathrm{~mm}^{3}\right)$ was used for data collection. Diffraction data were collected at $298(2) \mathrm{K}$ by $\omega$-scan technique on a Bruker SMART APEX II CCD diffractometer [23] equipped with $\mathrm{CuK} \alpha$ radiation $(\lambda=1.5418 \AA)$. The unit cell parameters were determined by the least-squares methods using 1292 reflections in the $2 \theta$ range $5.5^{\circ}-55.6^{\circ}$. The data were corrected for Lorentz-polarization and absorption effects [24]. The structure was solved by direct methods using the SHELXS program [25] and refined by a full-matrix least-squares calculation on $\mathrm{F}^{2}$ using SHELXL [25].

All $\mathrm{H}$ atoms were placed at calculated positions and treated using a riding model, fixing the $\mathrm{C}-\mathrm{H}$ distances at $0.96 \AA$ and $\left.\mathrm{U}_{\text {iso }}(\mathrm{H})=1.2 \mathrm{U}_{\mathrm{eq}}(\mathrm{C})\right]$, the $\mathrm{N}-\mathrm{H}$ distance at $0.86 \AA$ and $\left.\mathrm{U}_{\text {iso }}(\mathrm{H})=1.2 \mathrm{U}_{\mathrm{eq}}(\mathrm{N})\right]$. The final Fourier maps showed no peaks of chemical significance.

Figure 2 shows the molecular structure and the atom-

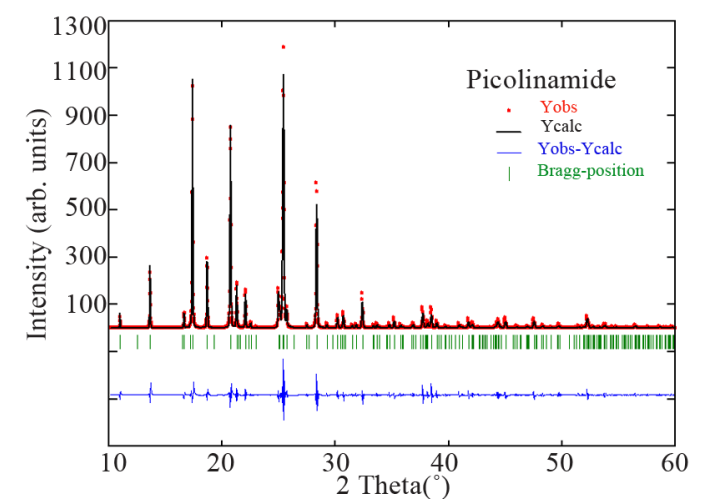

Figure 1. X-ray powder diffraction data for Picolinamide. The powder pattern was refined without structural model to confirm the unit cell parameters. labeling scheme of picolinamide. Table 1 shows the crystallographic data and structure refinement parameters. Selected bond distances, bond and torsion angles are listed in Table 2. Hydrogen bonds geometry is listed in Table 3.

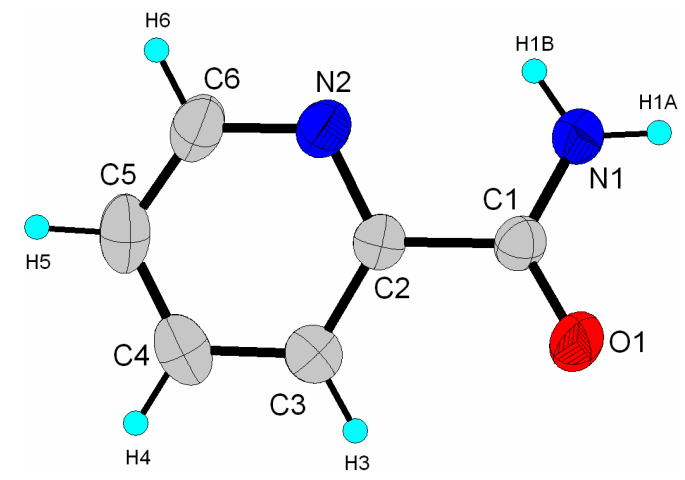

Figure 2. Molecular structure of the title compound showing the atomic numbering scheme. Displacement ellipsoids are drawn at $30 \%$ probability level. $\mathrm{H}$ atoms are shown as spheres of arbitrary radii.

Table 1. Crystal data, data collection and structure refinement.

\begin{tabular}{|c|c|}
\hline Chemical formula & $\mathrm{C}_{6} \mathrm{H}_{6} \mathrm{~N}_{2} \mathrm{O}$ \\
\hline Formula weight & 122.13 \\
\hline Temperature $(\mathrm{K})$ & 296 \\
\hline Radiation $(\AA)$ & $\mathrm{CuK}_{\alpha}(1.5418)$ \\
\hline Crystal system & Monoclinic \\
\hline Space group & $\mathrm{P} 2{ }_{1} / \mathrm{n}(14)$ \\
\hline$a(\AA)$ & $5.2074(1)$ \\
\hline $\mathrm{b}(\AA)$ & 7.1004(1) \\
\hline c $(\AA)$ & $16.2531(3)$ \\
\hline$\beta\left(^{\circ}\right)$ & $100.260(1)$ \\
\hline $\mathrm{V}\left(\AA^{3}\right)$ & $591.34(2)$ \\
\hline Z & 4 \\
\hline$d_{x}\left(g \mathrm{~cm}^{-3}\right)$ & 1.372 \\
\hline $\mathrm{F}(000)$ & 256 \\
\hline$\mu\left(\mathrm{mm}^{-1}\right) \mathrm{CuK}_{\alpha}$ & 0.807 \\
\hline Crystal size $\left(\mathrm{mm}^{3}\right)$ & $0.37 \times 0.20 \times 0.20$ \\
\hline$\theta$ range for data collection $\left({ }^{\circ}\right)$ & $5.5-57.4$ \\
\hline hkl range & $-5 \leq \mathrm{h} \leq 4 ;-7 \leq \mathrm{k} \leq 7 ;-17 \leq 1 \leq 17$ \\
\hline \multicolumn{2}{|l|}{ Reflections } \\
\hline Collected & 2946 \\
\hline Unique $\left(\mathrm{R}_{\text {int }}\right)$ & $777(0.015)$ \\
\hline With $\mathrm{I}>2 \sigma(\mathrm{I})$ & 663 \\
\hline Refinement method & Full-matrix least-squares on $\mathrm{F}^{2}$ \\
\hline Number of parameters & 83 \\
\hline $\mathrm{R}\left(\mathrm{F}^{2}\right)[\mathrm{I}>2 \sigma(\mathrm{I})]$ & 0.0389 \\
\hline$w \mathrm{R}\left(\mathrm{F}^{2}\right)[\mathrm{I}>2 \sigma(\mathrm{I})]$ & 0.1119 \\
\hline Goodness of fit on $\mathrm{F}^{2}$ & 1.06 \\
\hline $\operatorname{Max} / \min \Delta \rho\left(\mathrm{e} \cdot \AA^{-3}\right)$ & $0.15 /-0.12$ \\
\hline
\end{tabular}


Table 2. Selected geometrical parameters $\left(\AA ̊{ }^{\circ}\right)$.

\begin{tabular}{cccc}
\hline $\mathrm{C} 1-\mathrm{O} 1$ & $1.253(2)$ & $\mathrm{C} 1-\mathrm{N} 1$ & $1.317(2)$ \\
$\mathrm{C} 1-\mathrm{C} 2$ & $1.496(2)$ & $\mathrm{C} 2-\mathrm{C} 3$ & $1.386(2)$ \\
$\mathrm{C} 2-\mathrm{N} 2$ & $1.370(2)$ & $\mathrm{C} 6-\mathrm{N} 2$ & $1.334(2)$ \\
O1-C1-N1 & $124.0(1)$ & O1-C1-C2 & $120.7(1)$ \\
N1-C1-C2 & $115.4(1)$ & $\mathrm{C} 1-\mathrm{C} 2-\mathrm{N} 2$ & $117.2(1)$ \\
N1-C1-C2-N2 & $-18.1(2)$ & O1-C1-C2-N2 & $162.4(2)$ \\
N1-C1-C2-C3 & $162.0(2)$ & O1-C1-C2-C3 & $-17.5(2)$ \\
\hline
\end{tabular}

Table 3. Hydrogen bonds geometry $\left(\AA \AA{ }^{\circ}\right)$.

\begin{tabular}{|c|c|c|c|c|}
\hline D--H $\cdots A$ & D--H & $\mathrm{H} \cdots \mathrm{A}$ & $\mathrm{D} \cdots \mathrm{A}$ & D--H $\cdots A$ \\
\hline 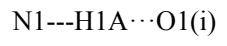 & 0.86 & 2.08 & $2.923(2)$ & 166 \\
\hline N1---H1B $\cdots$ O1(ii) & 0.86 & 2.41 & $3.033(2)$ & 130 \\
\hline
\end{tabular}

Symmetry codes: ${ }^{(\mathrm{i})} 1-\mathrm{x}, 2-\mathrm{y}, 1-\mathrm{z} ;{ }^{(\mathrm{ii})} 1+\mathrm{x}, \mathrm{y}, \mathrm{z}$.

Crystallographic data for the structure reported here have been deposited with the Cambridge Crystallographic Data Centre (Deposition No. CCDC-913526). The data can be obtained free of charge via http://www.ccdc.cam.ac.uk/perl/catreq.cgi.

\section{Results and Discussion}

A search in the Cambridge Structural Database (Version 5.33, August 2012) [19] shows only 5 structures with the picolinamide moiety. In the structures with code EYIXAL [26], FUGDER [27] and POVZEF [28] the picolinamide is a cation forming salts, and in EXAPEZ [29] picolinamide is a neutral molecule forming a co-crystal. PICAMD [18] corresponds with the earlier determination of the single amide molecule.

In our study, the pyridine ring is essentially planar, with maximum deviations of 0.010 in $\mathrm{C} 4$ and -0.010 in N2 (Figure 2). The dihedral angle formed between the pyridine ring and the amide plane is $18.26(9)^{\circ}$. This value is similar with the observed in the other picolinamide cations EYIXAL, FUGDER and POVZEF, but higher that 6.4(2) Å observed in the neutral molecule of co-crystal EXAPEZ.

Picolinamide molecule adopts a syn conformation with the heterocyclic $\mathrm{N}$ and amide $\mathrm{N}$ on same sides of the molecule [torsion angle N1-C1-C2-N2 $=-18.1(2)^{\circ}$ ]. This conformation is also observed only in the co-crystal EXAPEZ. When picolinamide is in cations form, EYIXAL, FUGDER and POVZEF, the molecule adopts an anticonformation.

The crystal structure of picolinamide displays an extended hydrogen-bond network generated by amide-amide synthons. Each picolinamide molecule is involved in two intermolecular N--O $\cdots$ H hydrogen bonds (Figure 3).

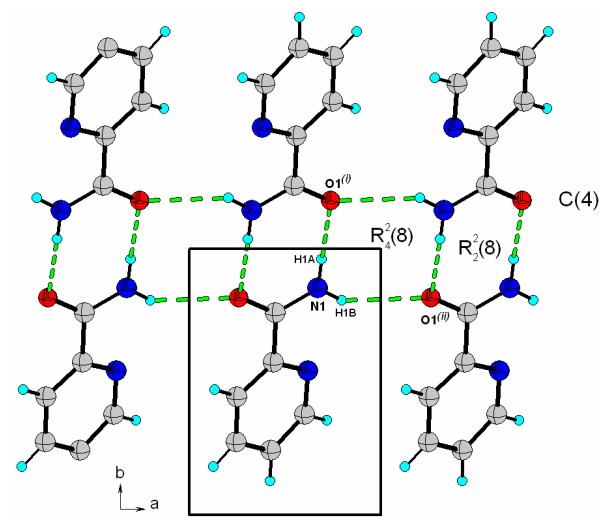

Figure 3. A portion of the crystal packing viewed in the ba plane. Intermolecular hydrogen bonds, $\mathrm{N}-\mathrm{-H} \cdot \mathrm{\cdots O}$ with symmetry (i) $1-x, 2-y, 1-z$ and (ii) $1+x, y, z$, are indicated by dashed lines.

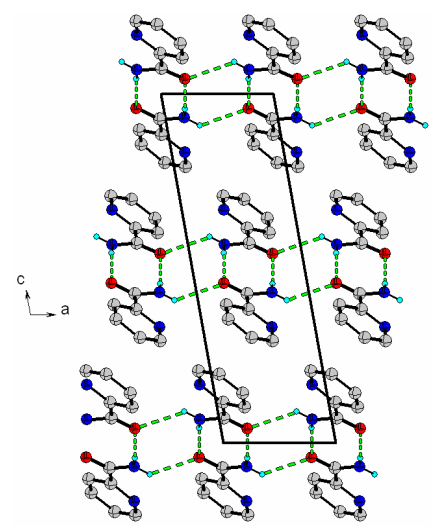

Figure 4. Crystal packing diagram in the ca plane. Intermolecular hydrogen bonds, $\mathrm{N}--\mathrm{H} \cdots \mathrm{O}$, are indicated by dashed lines. $\mathrm{H}$ atoms not involved in hydrogen bonding have been omitted for clarity.

These units are linked together through a complementary amide dimer $\mathrm{R}_{2}{ }_{2}(8)$ motif [30,31], formed by $\mathrm{N} 1--$ $\mathrm{H} 1 \mathrm{~A} \cdots \mathrm{O} 1$ at $(1-\mathrm{x}, 2-\mathrm{y}, 1-\mathrm{z})$. The chains are linked through a second complementary interaction formed by $\mathrm{N} 1-\mathrm{H} 1 \mathrm{~B} \cdots \mathrm{O} 1$ at $(1+\mathrm{x}, \mathrm{y}, \mathrm{z})$, resulting in the formation of ladders of alternating $\mathrm{R}_{4}^{2}(8)$ rings, and chain running in the [100] direction with graph-set C(4). The combination of these interactions generates an extended corrugated hydrogen-bonded sheet in the $c a$ plane (Figure 4).

\section{Conclusion}

Crystal structure of picolinamide has been redeterminated with greater precision and accuracy. The molecular structure and crystal packing are stabilized by intermolecular $\mathrm{N}--\mathrm{O} \cdots \mathrm{H}$ hydrogen bonds into an infinite onedimensional network.

\section{Acknowledgements}

This work was supported by CDCHTA-ULA (grants 
C-1755-B and C-1784-B), FONACIT (grant LAB97000821) and INZIT (grant LOCTI-2007-0003).

\section{REFERENCES}

[1] R. A. Olsen, L. Liu, N. Ghaderi, A. Johns, M. E. Hatcher and L. J. Mueller, "The Amide Rotational Barriers in Picolinamide and Nicotinamide: NMR and Ab Initio Studies," Journal of American Chemical Society, Vol. 125, No. 33, 2003, pp. 10125-10132. doi:10.1021/ja028751j

[2] C. B. Aakeroy, A. M. Beatty, B. A. Helfrich and M. Nieuwenhuyzen, "Do Polymorphic Compounds Make Good Cocrystallizing Agents? A Structural Case Study That Demonstrates the Importance of Synthon Flexibility," Crystal Growth \& Design, Vol. 3, No. 2, 2003, pp. 159-165. doi:10.1021/cg025593z

[3] P. Vishweshwar, A. Nangia and V. M. Lynch, "Molecular Complexes of Homologous Alkanedicarboxylic Acids with Isonicotinamide: X-Ray Crystal Structures, Hydrogen Bond Synthons, and Melting Point Alternation," Crystal Growth \& Design, Vol. 3, No. 5, 2003, pp. 783790. doi: $10.1021 / \operatorname{cg} 034037 \mathrm{~h}$

[4] A. Lemmerer, N. B. Bathori and S. A. Bourne, "Chiral Carboxylic Acids and Their Effects on Melting-Point Behaviour in Co-Crystals with Isonicotinamide," Acta Crystallographica, Vol. B64, No. 6, 2008, pp. 780-790. doi:10.1107/S0108768108034526

[5] J. Lu and S. Rohani, "Preparation and Characterization of Theophylline-Nicotinamide Cocrystal," Organic Process Research \& Development, Vol. 13, No. 6, 2009, pp. 1269-1275. doi:10.1021/op900047r

[6] A. Lemmerer, C. Esterhuysen and J. Bernstein, "Synthesis, Characterization, and Molecular Modeling of a Pharmaceutical Co-Crystal: (2-Chloro-4-Nitrobenzoic Acid): (Nicotinamide)," Journal of Pharmaceutical Science, Vol. 99, No. 9, 2010, pp. 4054-4071. doi:10.1002/jps.22211

[7] L. J. Thompson, R. S. Voguri, A. Cowell, L. Male and M. Tremayne, "The Cocrystal Nicotinamide-Succinic Acid (2/1)," Acta Crystallographica, Vol. C66, 2010, p. o421. doi:10.1107/S0108270110027319

[8] V. R. Hathwar, R. Pal and T. N. Guru Row, "Charge Density Analysis of Crystals of Nicotinamide with Salicylic Scid and Oxalic Acid: An Insight into the Salt to Cocrystal Continuum," Crystal Growth \& Design, Vol. 10, No. 8, 2010, pp. 3306-3310. doi:10.1021/cg100457r

[9] N. B. Bathori, A. Lemmerer, G. A. Venter, S. A. Bourne and M. R. Caira, "Pharmaceutical Co-Crystals with Isonicotinamide; VitaminB3, Clofibric Acid, and Diclofenac; and Two Isonicotinamide Hydrates," Crystal Growth \& Design, Vol. 11, No. 1, 2011, pp. 75-87. doi: $10.1021 / \operatorname{cg} 100670 \mathrm{k}$

[10] L. Fabian, N. Hamill, K. S. Eccles, H. A. Moynihan, A. R. Maguire, L. McCausland and E. Lawrence, "Cocrystals of Fenamic Acids with Nicotinamide," Crystal Growth \& Design, Vol. 11, No. 8, 2011, pp. 3522-3528. doi:10.1021/cg200429j

[11] B. Lou and S. Hu, "Different Hydrogen-Bonded Interactions in the Cocrystals of Nicotinamide with Two Aromatic Acids," Journal of Chemical Crystallography, Vol.
41, No. 11, 2011, pp. 1663-1668. doi:10.1007/s10870-011-0154-Z

[12] R. A. E. Castro, J. D. B. Ribeiro, T. M. R. Maria, M. Ramos Silva, C. Yuste-Vivas, J. Canotilho and M. E. S. Eusebio, "Naproxen Cocrystals with Pyridinecarbox-Amide Isomers," Crystal Growth \& Design, Vol. 11, No. 12, 2011, pp. 5396-5404. doi:10.1021/cg2009946

[13] S. Tothadi and G. R. Desiraju, "Unusual Co-Crystal of Isonicotinamide the Structural Landscape in Crystal Engineering," Philosophical Transactions of the Royal Society, Vol. A370, No. 1969, 2012, pp. 2900-2915. doi:10.1098/rsta.2011.0309

[14] E. Akalin and S. Akyuz. "Vibrational Analysis of Free and Hydrogen Bonded Complexes of Nicotinamide and Picolinamide," Vibrational Spectroscopy, Vol. 42, No. 2, 2006, pp. 333-340. doi:10.1016/j.vibspec.2006.05.015

[15] M. Bakilera, O. Bolukbasi and A. Yilmaz, "An Experimental and Theoretical Study of Vibrational Spectra of Picolinamide, Nicotinamide, and Isonicotinamide," Journal of Molecular Structure, Vol. 826, No. 1, 2007, pp. 6-16. doi:10.1016/j.molstruc.2006.04.021

[16] Y. Miwa, T. Mizuno, K. Tsuchida, T. Taga and Y. Iwata, "Experimental Charge Density and Electrostatic Potential in Nicotinamide," Acta Crystallographica, Vol. B55, No. 1, 1999, pp. 78-84. doi:10.1107/S0108768198007848

[17] J. Li, S. A. Bourne and M. R. Caira, "New Polymorphs of Isonicotinamide and Nicotinamide," Chemical Communications, Vol. 47, No. 5, 2011, pp. 1530-1532. doi: $10.1039 / \mathrm{c} 0 \mathrm{cc} 04117 \mathrm{c}$

[18] T. Takano, Y. Sasada and M. Kakudo, "The Crystal and Molecular Structure of Picolinamide," Acta Crystallographica, Vol. 21, No. 4, 1966, pp. 514-522. doi:10.1107/S0365110X66003396

[19] F. H. Allen, "The Cambridge Structural Database: A Quarter of a Million Crystal Structures and Rising," Acta Crystallographica, Vol. B58, No. 1, 2002, pp. 380-388. doi: $10.1107 / \mathrm{S} 0108768102003890$

[20] A. Boultif and D. Löuer, "Powder Pattern Indexing with the Dichotomy Method," Journal of Applied Crystallography, Vol. 37, No. 5, 2004, pp. 724-731. doi:10.1107/S0021889804014876

[21] A. Le Bail, H. Duroy and J. L. Fourquet, "Ab-Initio Structure Determination of $\mathrm{LiSbWO}_{6}$ by X-Ray Powder Diffraction," Materials Research Bulletin, Vol. 23, No. 3, 1988, pp. 447-452. doi:10.1016/0025-5408(88)90019-0

[22] J. Rodriguez-Carvajal, "Fullprof, version 5.3, LLB, CEACNRS," 2012.

[23] B. Saint, Bruker AXS Inc., Madison, 2009.

[24] B. Apex, Bruker AXS Inc., Madison, 2010.

[25] G. M. Sheldrick, "A Short History of SHELX," Acta Crystallographica, Vol. A64, No. 1, 2008, pp. 112-122. doi:10.1107/S0108767307043930

[26] I. Ucar, A. Bulut, O. Z. Yesilel and O. Buyukgungor, "Picolinamidium Squarate and Di-p-Toluidinium Squarate Dehydrate," Acta Crystallographica, Vol. C60, No. 8, 2004, pp. 0585-o588. doi:10.1107/S0108270104013964

[27] A. Nielsen, C. J. McKenzie and A. D. Bond, "2-Carbamylpyridinium Tetrachloridoferrate(III)," Acta Crystal- 
lographica, Vol. E65, No. 11, 2009, p. m1359. doi:10.1107/S1600536809040148

[28] K. Gotoh, H. Nagoshi and H. Ishida, "Hydrogen-Bonded Structures of the Isomeric 2-, 3- and 4-Carbamoylpyridinium Hydrogen Chloranilates," Acta Crystallographica, Vol. C65, No. 6, 2009, pp. o273-o277. doi:10.1107/S010827010901525X

[29] S. Ghosh, P. P. Bag and C. M. Reddy, "Co-Crystals of Sulfamethazine with Some Carboxylic Acids and Amides: Co-Former Assisted Tautomerism in an Active Pharmaceutical Ingredient and Hydrogen Bond Competition
Study," Crystal Growth \& Design, Vol. 11, No. 8, 2011, pp. 3489-3503. doi:10.1021/cg200334m

[30] M. C. Etter, "Encoding and Decoding Hydrogen-Bond Patterns of Organic Compounds," Account of Chemical Research, Vol. 23, No. 4, 1990, pp. 120-126. doi:10.1021/ar00172a005

[31] M. C. Etter, J. C. MacDonald and J. Bernstein, "GraphSet Analysis of Hydrogen-Bond Patterns in Organic Crystals," Acta crystallographica, Vol. B46, No. 2, 1990, pp. 256-262. doi:10.1107/S0108768189012929 